\title{
Los complejos urbanos transfronterizos en América Latina
}

\section{Transborder Urban Complex in Latin America}

Haroldo Dilla Alfonso*

Resumen

La presencia de manchas urbanas transfronterizas es un hecho sociológico en las fronteras latinoamericanas. Estas aglomeraciones son el producto de la activación de los flujos de capitales, bienes y personas a través de ellas, y de la formación de corredores y regiones transfronterizas. A partir de una recreación de algunos posicionamientos teóricos precedentes, este artículo discute la validez de una definición conceptual — complejos urbanos transfronterizosy propone un debate en torno a una serie de variables de análisis que dan cuenta de la naturaleza de las relaciones entre las ciudades componentes desde la demografía, la economía, la política y las relaciones sociales. Palabras clave: ciudades, fronteras, transfronterizo, intercambio desigual.

\begin{abstract}
The existence of cross-border urban areas is a sociological phenomenon that concerns Latin American borders. These settlements are the result of the activation of the flows of capital, goods and people through them and the formation of transborders corridors and regions. Based on a review of several previous theoretical positions, this paper discusses the validity of the conceptual definition of Transborder Urban Complex. Futhermore, it proposes a debate on a number of study variables that account for the nature of the systemic relationships between cities, including demographics, economics, politics, and social relations.

Keywords: cities, unequal exchange, borderland, transborder.
\end{abstract}

Recibido: 7 de enero de 2014.

Aceptado: 2 de octubre de 2014.

* Universidad Arturo Prat, Chile, Instituto de Estudios Internacionales (INTE). Dirección: Vicente Huidobro 3600, Depto. 507B, Macul, Santiago de Chile. Correo electrónico: hdillaalfonso@gmail.com 
Las fronteras son crecientemente un asunto urbano. Sobre eso nos informa un acucioso estudio conducido por Sergio Peña (2008) en el que, basado en informaciones geográficas y procesamientos estadísticos, se realiza un conteo de las ciudades ubicadas a menos de 50 kilómetros de alguna frontera internacional. El estudio registró 307 fronteras internacionales y 985 ciudades en torno a ellas. En Europa se encontraba $41 \%$-un continente muy urbanizado y con fuerte densidad de fronteras internacionales- seguida de África y América.

Si bien los datos estadísticos mencionados no son exactos, -el propio autor reconoce omisiones- y no indican una realidad sociológica - muchas ciudades están a menos de 50 kilómetros de una frontera pero sin vocación fronteriza-, sí revelan una situación de urbanización en regiones que, hasta hace medio siglo, eran poco pobladas, con predominio de población rural y relegadas por la geopolítica a los nada envidiables títulos de confines de la patria.

La razón de este cambio es la tendencia predominante de evolución de las fronteras desde líneas geopolíticas de separación, a espacios sociales de contacto. $\mathrm{O}$ si se quiere, pensando en términos de Glassner y de Blij (1980), el paso de sistemas relacionales divergentes a otros fundamentalmente convergentes. Y en consecuencia las fronteras, sin dejar de ser trincheras de contención de los otros, han pasado a funcionar también como puentes por donde transitan bienes, servicios, personas, informaciones y dinero. Han dejado de ser el final de algo para devenir centros de intermediación. Y si se quiere, adoptando el lenguaje político en boga, otras puertas de las patrias.

Bob Jessop (2001), en un artículo seminal, focalizó su atención en las implicaciones territoriales de estos procesos, donde convergen tres factores siempre en tensión: la vocación irrefrenable del capital para revalorizarse mediante la reestructuración espacial, la relativización del orden político internacional que hemos ido arrastrando desde Westfalia, y las interacciones sociales y culturales desde las comunidades. En consecuencia, para Jessop, asistimos a la proliferación de regiones transfronterizas que implican des-reterritorializaciones, re-escalamientos económicos y la emergencia de nuevas jerarquías espaciales en las que las manchas urbanas transfronterizas tienen papeles vitales. Y lo que resulta particularmente novedoso: vivimos una época en que esas regiones han dejado de ser 
meros resultados de las prácticas sociales o de las estrategias de acumulación para devenir metas de las políticas públicas.

Estas manchas urbanas que rebasan las fronteras y establecen especies de conurbaciones más o menos distantes físicamente, pero absolutamente compenetradas funcionalmente, son un dato imprescindible de los estudios actuales de fronteras. Y que implican la necesidad de acciones coordinadas de administración y gestión —es decir, de gobierno- entre las entidades involucradas.

El objetivo principal de este artículo es ofrecer una propuesta de conceptualización de este fenómeno urbano en América Latina, que hemos denominado como Complejos Urbanos Transfronterizos (CUT) y definidos a partir de seis condiciones. Su intención no es fijar un concepto definitivo, sino contribuir a un debate académico que ha resultado intenso y fructífero, pero excesivamente focalizado a las experiencias: europea, norteamericana y más recientemente de Asia Oriental. ${ }^{1}$ Imposibilitado - por razones de espacio- para recorrer este debate en toda su magnitud (Kolossov, 2005; Anderson y Dowd, 1999; Perkman y Ngai Ling Sum, 2001; Leimbruger, 2005; Sohn, 2013 y 2014; Herzog y Sohn, 2014, entre otros), he preferido fijar mi atención en sus orígenes, cuando en los años noventa, académicos europeos, norteamericanos y latinoamericanos comenzaron a discutir la realidad sistémica contenida en las ciudades que yacían, en estrechas interrelaciones, a ambos lados de las líneas fronterizas.

\section{Desempolvando un debate larvado}

Los acontecimientos de los años noventa invitaban a creer que las fronteras se estaban acabando. La caída del Muro de Berlín y la disipación de

${ }^{1}$ Aquí vale la pena una aclaración. Obviamente, hay una producción latinoamericana sobre el tema, una parte de la cual es citada a lo largo del artículo. Pero que ha sido una producción académica más pródiga en estudios particulares que en intentos de generalizaciones y construcciones conceptuales. Esta producción latinoamericana, por otra parte, resulta menos accesible, sobre todo cuando se genera desde universidades ubicadas en provincias. A su favor, diría que a diferencia de la academia norteamericana y europea, que regularmente constriñe sus referencias al mundo noratlántico, y ni siquiera se toma el trabajo de revisar la bibliografía en castellano, la producción latinoamericana ha mostrado, en este sentido, una vocación menos localista. 
la Unión Soviética precipitaron los proyectos integracionistas en Europa, lo que desembocó en 1993 en el Tratado de Maastricht. Simultáneamente lubricó con recursos y un plan de largo plazo a los programas integracionistas al estilo de EuroReg y PHARE, que pretendían forjar una Europa de Regiones sobrepuestas a las cicatrices de Westfalia.

En el Nuevo Mundo, mexicanos, americanos y canadienses se aprestaban a firmar el mayor acuerdo de libre comercio de la historia, el Tratado de Libre Comercio de América del Norte (TLCAN), mientras que el llamado Consenso de Washington puso sobre la mesa la noción del Regionalismo Abierto y se organizaron proyectos integracionistas de diferentes matices. Desde Asia, siempre con la discreta meticulosidad de sus culturas ancestrales, varios estados comenzaron a ensayar refuncionalizaciones de las fronteras internacionales; el mejor ejemplo de lo cual ha sido el ya clásico sIJORI, que puso a la fuerza de trabajo y los recursos naturales de Malasia e Indonesia en función de la vigorosa economía de Singapur.

La academia fue sacudida por este jaque al orden de los Estados Nacionales. Las universidades y tanques pensantes financiaron programas académicos dirigidos a dar cuenta de este fenómeno, lo que produjo una infinidad de estudios con posicionamientos diversos y también diversos niveles de densidad teórica. Desafortunadamente, los estudios que han quedado señalizando este momento intelectual no fueron los más sofisticados, sino las piezas más sencillas, diría que divulgativas, fuertemente comprometidas con el cosmopolitismo neoliberal y carentes del don del quizás. Una de ellas escrita por Ohmae (1991), que sintetizó un discurso globalifílico sin sonrojos: un sistema mundial sin vencedores ni vencidos y un "mundo sin fronteras [donde] cada día resulta más difícil determinar en qué consisten los intereses nacionales tradicionales" (p. 197).

Es razonable creer que estos contextos políticos y académicos tan optimistas hayan sido idóneos para la proliferación de conceptualizaciones que enfatizaban las dinámicas fusionistas de las fronteras. Y, en particular, que focalizaban su atención en el fenómeno sociológico más afectado por estos procesos: las ciudades.

Desde Europa llegó el producto teórico más audaz y probablemente el menos fundamentado: el concepto de ciudades binacionales. Sus arquitectos, ligados al centro de estudios fronterizos de la Universidad de Nijmegen (Nimega) en Holanda y muy cerca de su frontera con Alemania, basaron 
su apreciación en la voluntad de dos ciudades ubicadas en esa frontera -Kerkrade y Herzongenrath-de formar un solo cuerpo administrativo y adoptar un nuevo nombre: Eurode. El ejemplo de Eurode produjo unas pocas réplicas, y más limitadas en sus alcances, en la frontera polaca/alemana y belga/holandesa, lo que llevó a los académicos de Nijmegen a creer que estaban en presencia de un fenómeno político generalizable.

Pero la experiencia de Eurode era tan específica que resultaba inusual. Las dos ciudades coaligadas eran una sola realidad histórica, dividida por una cerca dictada por la geopolítica europea, pero fácilmente franqueable. Había una considerable homogeneidad cultural y una experiencia de contactos políticos que fueron acelerados por los boyantes programas integracionistas (Ehlers, 2001). De ahí que el concepto ciudad binacional nunca rebasó el plano descriptivo de los síntomas: "[...] ciudades dobles que están divididas por una frontera nacional, que comparten un entorno y cuyos habitantes tienen un sentido de pertenencia conjunta" (Ehlers y Buursink, 2000, p. 189). Y los estudios que sobre el tema realizaron los académicos holandeses han quedado como una interesante contribución teórica sobre los alcances y límites de los factores subjetivos - discursos, identidades, recursos simbólicos-en los procesos de integración pero menos relevantes en relación con otras variables claves que condicionan los comportamientos de las manchas urbanas ubicadas sobre las fronteras.

En el mismo momento en que los europeos comenzaban a interrogarse sobre las implicaciones de Eurode, en la frontera México-Estados Unidos varios académicos estaban produciendo obras que, varios lustros después, siguen siendo referencias tan imprescindibles como controversiales de los estudios de fronteras.

Una parte de estos estudios centraba su atención en la manera en cómo la intensificación de contactos binacionales estaba produciendo una nueva realidad transfronteriza. Aunque se trató de estudios de solidez intelectual que obviaron con éxito los acercamientos teleológicos simples, al estilo del mundo-sin-fronteras de Ohmae, es también innegable que todos los casos estuvieron animados por una cierta vocación organicista que tomaba a la separación como punto de partida y preveía la apertura, el mestizaje y el biculturalismo como datos definitorios de un mundo mejor en construcción. Todos reconocían la desigualdad y la tensión que de ella se derivaba, 
pero la calibraron como un fenómeno adjetivo que podía ser mitigado en la propia integración, sin tener en cuenta que la asimetría era condición para la integración. La faceta del contacto que toda frontera posee terminó invisibilizando la otra faceta ineludible: la separación.

Probablemente el mejor ejemplo de esta tendencia fueron los valiosos estudios antropológicos conducidos por Oscar Martínez (1994). Para Martínez la frontera binacional se componía de una serie heterogénea de articulaciones regionales, pero que tenían en común estar expuestas a lo que denominaba un "ambiente transnacional” (transnational milieu). Este ambiente estaba caracterizado por una serie de situaciones que implicaban tanto los conflictos como sus resoluciones, la convivencia como la separación.

Con el ánimo de organizar sus evidencias y generalizar desde la heterogeneidad, Martínez construyó una serie de tipos ideales, que han devenido conceptos en la producción académica posterior, y han sido discutidos como tales. Un ejemplo de ello es su tipología de fases de desarrollo fronterizo, evidentemente incompleta y viciada de la ya mencionada perspectiva organicista en que la frontera se mueve desde un estadío primario de cierre hacia otro superior de apertura. Ello es también visible en su enjundiosa clasificación de mexicanos, mexicano-americanos y angloamericanos en cerca de tres decenas de tipos que, como la frontera misma, evolucionan desde la asepsia nacionalista hasta niveles superiores de mestizaje y vocación transnacional. Es interesante anotar que en toda su obra Martínez no hace una distinción entre la relación transfronteriza y la relación transnacional, dos categorías frecuentemente intercambiadas en la presentación, más con fines estéticos que conceptuales.

Martínez exploró algunos temas urbanos, y de hecho casi todos los tipos que construyó eran de hábitats citadinos. Presentó las "ciudades gemelas" como "entidades unificadas a pesar de la división impuesta por los límites internacionales", y como la quintaesencia de los "sistemas binacionales altamente interdependientes". Pero sólo utilizó a las ciudades como referencias sin prestar atención particular al problema de la interacción urbana en la frontera. Incluso prestó poca atención al hecho de que cuatro años antes de su libro otro académico norteamericano, Lawrence Herzog (1990), había publicado otro libro imprescindible bajo el sugerente título de Donde el norte se encuentra con el sur. 
Herzog realizó el mejor y más exhaustivo recuento de la situación urbana transfronteriza -entendida como sistemas relacionales- hecho hasta el momento, lo que convirtió su libro en un punto obligado de referencia. Pero centró su análisis en el par Tijuana-San Diego; sin lugar a dudas el dúo paradigmático del borde. Desde aquí elaboró un concepto que ha sobrevivido, envuelto en vivas polémicas, hasta nuestros días: las metrópolis transfronterizas. Para Herzog (1990), una metrópoli transfronteriza era:

[...] una zona urbanizada compuesta por un asentamiento de Estados Unidos al norte de la frontera y un asentamiento mexicano al sur. El área urbanizada está fusionada en un solo dominio espacial funcional, unificado por actividades cotidianas, recursos naturales compartidos y características ambientales. Y un mercado laboral que solapa el borde político (p. 139).

No se trataba de una relación lineal. En su estudio Herzog dedicó más de un espacio a discutir sobre las disparidades existentes en una relación desigual y en el propio título de su libro los vocablos "sur" y "norte" no describen latitudes, sino condiciones socioeconómicas. Y desde estas disparidades derivó elementos de "fricción" y de "fusión" que someterían las relaciones transfronterizas a tensiones, avances y retrocesos. Pero en cualquier caso, lo que resultaba medular en el análisis de Herzog era la idea de que "las ciudades fronterizas han resultado tan conectadas funcionalmente, que sus futuros están ineludiblemente ligados, independientemente de si los gobiernos nacionales pueden establecer procedimientos formales para incidir en los problemas fronterizos" (1990, p. 140).

De todas maneras, es evidente que Herzog no intentó la creación de un concepto con fines analíticos - ello le hubiera obligado a caracterizar más detalladamente sus "metrópolis transfronterizas" - sino simplemente cubrir un vacío terminológico con un vocablo tan vago que finalmente resultó poco feliz; y fue acerca de esta infelicidad sobre la que se pronunció Tito Alegría en varios de sus mejores escritos.

En 1992 Alegría había publicado su Desarrollo urbano en la frontera México-Estados Unidos, una obra en la que desbrozó importantes aspectos de la relación transfronteriza, concepto que diferenció expresamente de la dimensión transnacional, y que en muchos sentidos, constituye una obra 
seminal en los estudios latinoamericanos de fronteras, sólo que, incorporado como "sentido común" académico, sus aportes han sido más conocidos que reconocidos.

El punto fuerte del libro es una crítica de las relaciones transfronterizas desde la economía política y la geografía urbana, marcadas por la desigualdad y la asimetría. En consecuencia, si en los autores norteamericanos la frontera es vista como apertura, aquí es enfatizada, con un razonable pesimismo, como "línea selectiva":

Ambos procesos, el de relación complementaria asimétrica y el de freno selectivo, han sido las formas de expresión de lo estructural y más sustantivo que han marcado el actual carácter de las ciudades de la frontera mexicana; la contigüidad de las diferencias (Alegría, 1992, p. 42).

Vale la pena anotar que la diferencia y la asimetría apuntadas por Alegría no estaban referidas a situaciones contrastantes, como había sido usual en la producción norteamericana, sino a relaciones que reforzaban ambas condiciones. Y en consecuencia, da un viraje muy sugerente al sentido de los "subsistemas urbanos binacionales" que se generaban en torno a la línea fronteriza:

Las complementariedades basadas en las diferencias estructurales [anotaba el autor] se intensifican selectiva y conflictivamente [...] La intensidad surge de los mecanismos de mercado, la selección emerge tanto de la regulación en la esfera económica como de políticas traducidas en reglamentos; y el conflicto, de la confrontación de diversos intereses englobados en dos regulacionesreglamentaciones distintas (p. 46).

Pero no fue hasta el presente siglo que Alegría $(2000,2008)$ articuló una crítica específica a los que aquí llamaremos planteamientos "fusionistas” y que habían continuado desarrollándose tras las obras mencionadas. ${ }^{2}$

${ }^{2}$ Algunos de ellos han sido incitantes piezas de gran rigor metodológico, por ejemplo el polémico artículo de Robert Alvarez (1995) en que proyecta los estudios antropológicos fronterizos norteamericanos como un paradigma, o el libro colectivo coordinado por Dear y Leclerc (2003) en el que se acuña el término Bajalta California como expresión de un orden de ciudades post-fronterizas. Y motivaron otras respuestas críticas 
Alegría centró su atención crítica en la obra de Herzog y en particular en la supuesta existencia de "metrópolis transfronterizas" en el borde mexicanoestadunidense. Pero lo hizo con tal fuerza que terminó por poner en duda cualquier rasgo sistémico en las aglomeraciones urbanas con las que trataba. Y en consecuencia, negando implícitamente puntos fuertes de su propia obra anterior.

En lo fundamental, Alegría descartaba la existencia de una "metrópoli transfronteriza" a partir de tres situaciones que consideraba vitales: no hay una ecología urbana única, los mercados fronterizos no están integrados y hay diferencias abismales en términos de gestión territorial y planificación urbana (2008). Todo lo cual le llevaba a afirmar que:

La intensa interacción interurbana entre Tijuana y San Diego no permite la convergencia urbana porque las diferencias entre esas ciudades dependen de condiciones nacionales y no de condiciones locales [...] Sólo habrá metrópolis transfronterizas cuando las economías de ambos países sean menos diferentes y las regulaciones nacionales sean menos restrictivas a la interacción transfronteriza (pp. 161-162).

No faltan razones en los argumentos de Alegría acerca de la preeminencia de una serie de factores de "reforzamiento" de la separación que frenan la interacción, o la convierten en una relación de subordinación que denuncia la interdependencia asimétrica como eje del relacionamiento binacional. Pero hay menos razones para considerarles impedimentos fatales para la formación y funcionamiento de sistemas urbanos transfronterizos.

La perspectiva sistémica organicista — cara al funcionalismo sociológico- que animaba curiosamente a las dos partes en controversia, no es un recurso teórico útil para acercarnos a las asimetrías y contradicciones que determinan a la inmensa mayoría de las conurbaciones urbanas transfronterizas que contabilizaba Peña (2008). Y por consiguiente estos sistemas

del lado latinoamericano, como fueron los casos de Grimson (2000) y Vila (2000). Desafortunadamente el espacio disponible y la especificidad del foco que condiciona este artículo, me impiden profundizar en este interesante despliegue de posiciones dispares que curiosamente nunca fructificó en un debate explícito, lo que sin duda todos hubiéramos agradecido. 
urbanos sólo pueden ser aprehendidos, recordando una certera expresión de Alejandro Grimson (2000), como sistemas relacionales basados en el conflicto.

Valga anotar que algunas de las principales objeciones de Alegría al concepto de metrópoli transfronteriza resultan perfectamente identificables en cualquier ciudad dentro de un mismo espacio nacional. Factores como la diversidad de prácticas sociales, la coexistencia de códigos de comunicación diferentes, la fragmentación de los mercados e incluso la inexistencia de un mecanismo único de gobierno son visibles en muchas ciudades contemporáneas. Y eso no las cuestiona como ciudades, sólo que estamos obligados a aprehenderlas en la diversidad generada desde la fragmentación socioespacial.

Por otro lado, ninguno de los autores tomaba suficientemente en cuenta un dilema planteado por Jessop (2001): la existencia de una tendencia vital en las regiones fronterizas que implica la desestatización de los regímenes fronterizos. De manera que cualquier evaluación sobre la compartición de responsabilidades de gestión incluye crecientemente a los actores locales, y dentro de ellos a una serie de organizaciones no estatales que conforman redes relacionadas con temas como medio ambiente, derechos humanos, mercados y cultura. Una mirada más exhaustiva a este fenómeno no nos llevaría a revalidar la noción metropolitana de Herzog, pero tampoco el desierto institucional de Alegría.

Como antes apuntaba, desafortunadamente nada de esto implicó un debate, lo que impidió un intercambio más sofisticado. Pero a pesar de ello, los estudios fronterizos continuaron dando cuenta de las manchas urbanas binacionales, proveyendo denominaciones funcionales y sobre todo alertando sobre la necesidad de pensar formas transfronterizas de gestión espacial para lo que efectivamente era un fenómeno transfronterizo.

\section{Para continuar avanzando:}

\section{Notas para una metodología de análisis}

En artículos anteriores he propuesto el término complejos urbanos transfronterizos (CUT) (Dilla, 2008) para designar el fenómeno que aquí nos ocupa. El uso de la palabra complejo sugiere una connotación suficientemente 
amplia para indicar niveles diversos de interacciones y por tanto también de conformación sistémica. La palabra transfronterizo, por su parte, indica una relación que específicamente involucra a los actores locales o localizados de las comunidades en interacción. Es decir, un término flexible que pueda dar cobertura conceptual a una variedad de situaciones específicas. Pero más allá del asunto meramente terminológico, lo que pudiera ser más interesante en la conceptualización del cuT es que se construye sobre una serie de seis variables que pueden mostrar grados diferentes de desarrollo en cada experiencia concreta. De manera que la principal respuesta que podemos obtener de esta discusión no es si un par urbano sobre un borde es o no un CuT, sino en qué medida lo es, o no, y sobre todo de qué manera lo es, o no.

Los CUT, por consiguiente, se definen como sistemas complejos y contradictorios a partir de los siguientes indicadores cualitativos:

1. Compartición de un mismo medioambiente. Por razones elementales, tiene que haber cercanía geográfica entre los centros urbanos. Ello no significa adyacencia (de ahí la imprecisión del término conurbación), pero sí proximidad suficiente como para compartir un mismo espacio ambiental y una serie de recursos naturales vitales para las ciudades. Y si tenemos en cuenta que muchas fronteras se definen mediante las mal llamadas "fronteras naturales" que implican usos acordados de recursos - por ejemplo el agua de los ríos-, entonces llegamos a la conclusión de que se trata de un asunto de primer orden. En algunos lugares — como es el caso de la accidentada frontera que, por tramos, comparten Brasil, Paraguay, Argentina y Uruguay- es un asunto que adquiere connotaciones internacionales de fuertes efectos mediáticos (Montenegro y Giménez, 2006; Bello, 2012).

No creo que sea posible establecer una tabla de proximidades que clasifique los CUT. Unos pocos kilómetros en poblados separados por cordilleras es un impedimento crucial para el contacto, pero en la frontera México-Estados Unidos significan una vecindad incitante.

2. Articulaciones espaciales diversas. Todo poblado fronterizo está expuesto a tantos roles de intermediación como espacios en que se 
constituye, y de ahí su fuerte connotación heterotópica. Una ciudad como Arica, en la frontera chilena con Perú, no es solamente una bisagra que conecta a la economía del norte chileno con el sur peruano, sino también un entrepot comercial que, al decir de Aranda, Oviedo y Corder (2010), la proyectan como un puente entre el mercado sur asiático y la subregión sudamericana. Más complicada aún es la situación del trifinio donde confluyen Foz de Iguazú, Puerto Iguazú y Ciudad del Este, una triple frontera en la que comercio y geopolítica forman una enrevesada madeja de intrigas y campañas mediáticas que Bello (2012) ha descrito de manera muy sugerente. ${ }^{3}$

El artefacto conceptual que nos permite explicar y dar una racionalidad a todas esas intermediaciones y roles espaciales de las ciudades fronterizas son los corredores transfronterizos, entendidos como encadenamientos jerárquicos espaciales en los que las ciudades actúan como centros de provisión de servicios, bienes, capitales e información, en diferentes escalas y de diferentes maneras (Félix, Zepeda y Castro, 1996). En este sentido, los CuT son regiones particularmente sensibles de estos encadenamientos espaciales, pues son ellos los que garantizan la continuidad transfronteriza de los corredores. La magnitud y calidad de estos corredores depende de factores como el tipo de interacción que canalizan, la intensidad de los flujos y la propia fisonomía espacial implicada. Pero hay dos cualidades que vale mencionar.

La primera es que aunque toda interacción transfronteriza incluye actividades diversas, la manera en cómo esas actividades se comportan determinará el carácter del corredor. Hay corredores muy activos pero que limitan fundamentalmente su actividad a los flujos de mercancías y con relacionamientos políticos y culturales puntuales; pero otros, evolucionan hacia formas superiores de interdependencia involucrando actividades productivas relacionadas con la condición transfronteriza, al mismo tiempo que alimentan

${ }^{3}$ Tal solapamiento de espacios contradictorios sobre un mismo lugar es lo que produce ese efecto fronterizo que llamó la atención de Bauman (2004), en que resulta fútil cualquier intento de dar un único sentido territorial a los conflictos, y en que "los cercos y empalizadas, más que dar cuenta de una realidad, son una declaración de intenciones" (p. 116). 
otros flujos extraeconómicos. Cuando esto último sucede, podemos hablar de la existencia de regiones transfronterizas y de cuT con roles adecuados a ello (Dilla, 2007).

La segunda acotación se refiere a las diferencias de relación espacial que un corredor o región transfronteriza depara a cada una de las ciudades. Regularmente la ciudad más pobre del cuT está más involucrada en la relación transfronteriza debido a que experimenta una suerte de colonización en beneficio de las ciudades dominantes del corredor y de su par en el cut. Lo es tanto Tijuana con sus maquilas que tributan a las industrias de tecnología de punta de San Diego, como Ciudad del Este como proveedora de reexportaciones baratas al subcontinente brasilero. Hacia ellas concurren inversiones diversas y funcionan como lugares privilegiados de transacciones, aunque sólo marginalmente de acumulación. En cambio, las ciudades ubicadas en el lado fuerte tienen siempre funciones transfronterizas más discretas y operan como "factorías" similares a los pontones mercantiles europeos en Asia continental.

Por esta razón, y porque están en contacto con regiones más ricas, las ciudades del lado débil son regularmente más pobladas y ofrecen una imagen de mayor dinamismo que la parte fuerte del binomio. También suelen ser capaces de movilizar mejor a sus hinterlands inmediatos. Pero nada de ello omite una cualidad ineludible de los cuT: el intercambio desigual, es decir, la transferencia neta de plusproducto de una parte a la otra.

3. Interdependencia económica. La definición de esta condición habla de una relación (en última instancia) de mutua conveniencia que condiciona la reproducción material de las ciudades involucradas pero no la define in toto. Es decir, que la compenetración económica de las dos ciudades nunca es absoluta, y en cada una habrá actividades que miran a cada realidad nacional y no dependen de la relación transfronteriza. Las economías urbanas, por tanto, se muestran como solapamientos de actividades diversas, pero en las que las actividades primarias de cada ciudad se derivan de la relación con la otra.

Es un asunto complicado y de muchas aristas, de las que me interesa puntualizar dos. 
La primera es destacar que hay una diferencia crucial entre la relación interurbana que se establece desde los grandes flujos comerciales binacionales y desde la miríada de redes de intercambios y de consumos de servicios marcados por la informalidad y el subregistro. Los primeros son los que otorgan visibilidad estadística a los CUT, pero pocas ventajas a cambio de la digestión de una serie de externalidades negativas derivadas del tráfico vehicular, la militarización y la operación a gran escala de bandas mafiosas. Desde los segundos se derivan empleos, abaratamiento del consumo y redes sociales binacionales que impactan fuertemente en la vida local.

Esta diferencia es crucial para entender algunas disparidades que asoman en las ciudades de las fronteras. Por ejemplo, el par Laredo-Nuevo Laredo constituye el cut que arropa los flujos mercantiles mayores de la frontera México-Estados Unidos y posiblemente del mundo. Por sus aduanas transita algo más del $40 \%$ de los valores lícitos que circulan por esa frontera. Pero son al mismo tiempo ciudades muy pobres (Laredo figura entre las diez ciudades más pobres de Estados Unidos) y con niveles de criminalidad superiores a otras semejantes. Más al sur, sobre el Caribe, Jimaní-Mal Passe es el principal puerto terrestre dominico-haitiano con $60 \%$ del tráfico. Pero al mismo tiempo Jimaní es una ciudad inhabilitada y la más pobre de los puertos comerciales del borde. Un auténtico no-lugar por el que transitan camiones inmensos que se detienen en las oficinas públicas el menor tiempo posible. Nadie va a Jimaní: todos pasan por ella.

Otra cuestión tiene que ver con la asimetría de la relación. Por muy desagradable que pueda resultar la constatación de la desigualdad entre las ciudades en contacto, habría que precisar que esta desigualdad ha sido en todos los lugares una condición de las relaciones económicas entre ellas. Dicho en otras palabras: sólo a un nivel suficiente de desigualdad, las ciudades fronterizas ensayan relaciones estables e intensas de intercambios, en la misma medida en que se expanden las oportunidades de ganancias diferenciales. En este sentido, aunque la relación económica se asienta sobre "intereses materiales antagónicos" - recordando la acertada expresión de Wright (1994) sobre las clases_, las partes menos favorecidas la 
aceptan siempre que ello implique oportunidades de sobrevivencia y acumulación marginal.

Con ello no quiero decir que no haya oportunidades de complementariedades en relaciones relativamente simétricas. La ciudad de Cúcuta en Colombia y el eje urbano San Antonio-Ureña-San Cristóbal conforman una mancha urbana de más de un millón de habitantes y sirven de asiento al puerto terrestre más importante de Sudamérica, con unos 3000 millones de dólares de valores traficados legalmente. Constituyen un típico CUT, alimentado por un activo comercio local, de bienes, servicios y de trabajo, pero las diferencias socioeconómicas entre ellas no son tan agudas como para constituir un atractivo diferencial estable. ${ }^{4}$ Por ello, a pesar de la intensidad del tráfico y de la comunidad cultural, las relaciones económicas usualmente no rebasan el plano comercial, y se ven sujetas a variaciones oportunistas debido a factores políticos y de canjes monetarios (Valero, 2002, 2008). En ocasiones de una manera tan drástica que implica la traslación de los mercados de uno a otro lado del río Táchira que le sirve de "frontera natural".

Esta situación contrasta con la observada en zonas fronterizas de mayores niveles de desigualdad, como son, para poner algunos ejemplos, las que comparten México y Estados Unidos, Haití y República Dominicana, y Brasil y Paraguay. En estos lugares las relaciones económicas se han establecido como una constante asimétrica que en ocasiones ha ido rebasando el plano estrictamente comercial, aprovechando las ganancias diferenciales en el lado débil como consecuencia del precio menor de la fuerza de trabajo, la flexibilidad de los controles ambientales y las exenciones fiscales, entre otras ventajas.

Sohn (2014), desde la realidad europea, ha constatado una situación similar en el eje que comparten Basilea, Ginebra y Luxemburgo, pero donde anota una diferencia que vale la pena tomar en cuenta: la transformación de los espacios fronterizos desde "modelos geoeconómicos" a "proyectos territoriales". Mientras los primeros

${ }^{4}$ Las relaciones fronterizas en esta región parecen ser tan "simétricas" y "equilibradas" que Bitar (2011) ha desechado considerar aquí la existencia de cualquier práctica de intercambio desigual o de representaciones negativas del otro. 
se apoyan exclusivamente en la explotación de los beneficios diferenciales, los segundos implican fuertes cargas simbióticas, transferencias tecnológicas y cooperación. Seguramente cualquier lector latinoamericano advertirá que hablar en nuestro continente de este segundo "tipo ideal" puede resultar un ejercicio de optimismo exagerado. Pero probablemente podrán encontrarse intenciones de esta naturaleza en las interacciones transfronterizas continentales si las asumimos más como tendencias que como modelos.

4. Existencia de relaciones sociales primarias intensas entre los pobladores de ambas ciudades. La vida de cualquier CUT -incluyendo aquellos permeados por prédicas xenófobas en casos de sociedades que se definen a sí mismas de forma antitética- es un enjambre de cruces, intercambios y comparticiones. Los paraguayos de Ciudad del Este y Encarnación, los haitianos de Ouanaminthe y los nicaragüenses de San Carlos usan los servicios médicos y educacionales del otro lado, con la misma intensidad como los habitantes de Foz de Iguazú, Los Chiles, Posadas y Dajabón hurgan en los mercados más baratos de sus contrapartes fronterizas y eventualmente aprovechan las oportunidades lúdicas de ciudades más activas y permisivas que las propias. Es la misma historia de los americanos que visitan cada día Tijuana, sea para comprar medicinas sin recetas, para cabalgar en los apacibles burritos disfrazados de cebras o para hundirse en las ergástulas de drogas y sexo barato de la Avenida Revolución.

Son prácticas sociales que revelan tantas solidaridades como cálculos egoístas de beneficios, pero al margen de todo ello, son parte de las fuentes de energía más importantes que tiene un CuT. Fue a esto a lo que Óscar Martínez (1994, p. 60) apuntó cuando disertó sobre una dimensión identitaria de "fronterizos transnacionales", afirmación ciertamente polémica pero sin recurso, a la cual, no pueden ser explicados los CuT y las sujetividades que les animan y les permiten sobrevivir a todas las contingencias, políticas y mercuriales.

Finalmente, me detengo brevemente en la relación que puede haber entre el funcionamiento más activo de un cuT y la homogeneidad cultural transfronteriza. La mayor parte de las fronteras de 
América Latina se caracterizan por la compartición de rasgos culturales e incluso por la maduración de perfiles culturales propios que revalidan con fuerza aquel axioma de que los fronterizos siempre se parecen más entre sí que los habitantes de las capitales que los gobiernan.

Hay casos históricos en que las regiones transfronterizas pugnaron en algún momento por constituirse en naciones o regiones autónomas, por encima de los bordes constituidos, como ha sido el caso, para poner un ejemplo, de Táchira el Norte de Santander en Venezuela-Colombia, tal y como nos ha relatado Bustamante (2004). Otros, nos informan de culturas ancestrales que fueron artificialmente divididas por bordes coloniales y que en la actualidad retoman sus identidades y desarrollan prácticas de paradiplomacia de alto valor simbólico y práctico, como es el caso de las comunidades aymarás en la frontera chileno-boliviana (Rouviere, 2009; Aranda, Ovando y Corder, 2010).

Sin embargo, las evidencias empíricas sugieren que si bien la homogeneidad cultural es un escenario positivo, no es suficiente para generar interacciones que conduzcan a la maduración del cuT.

Buursink (2001) ha expuesto un caso paradigmático al respecto: las dos ciudades del Niágara situadas, una junto a la otra, en Estados Unidos y Canadá. Ambas ciudades comparten longevidades similares, el mismo idioma, un mismo recurso (las cataratas) y hasta una apariencia común, combinando secciones "urbanalizadas" - como descritas por Muñoz (2008): limpias, divertidas y seguras-y zonas más extensas de habitación con visibles rasgos de degradación. Aparentan ser, afirma el autor, dos ciudades gemelas formalmente perfectas, pero en realidad constituyen una pareja que vive separada. Sencillamente porque ninguna tenía algo que ganar en contacto con la otra.

5. La percepción de mutua necesidad. La interacción social y el despliegue de prácticas sociales transfronterizas no implican, como aspiraba la definición de las "ciudades binacionales", que los habitantes de los CUT tengan un "sentido de pertenencia conjunta" (Ehlers y Buursink, 2000, p. 189). Aspirar a que los vecinos de El Paso se sientan parte de lo mismo que sus vecinos mexicanos de 
Ciudad Juárez, parece una meta lejana. Lo que con toda seguridad perciben los habitantes de uno y otro lugar - al menos aquellos que viven la transfrontericidad - es que son dos comunidades ligadas por lazos diversos, sin los cuales las cosas irían peor a ambas. Es decir, se perciben como mutuamente imprescindibles.

De Jesús (2010) realizó un estudio en la ciudad fronteriza dominicana de Dajabón. Lo que halló fue una suerte de rechazo/aceptación escalonada hacia los haitianos. Casi todos los dominicanos entrevistados querían trabajar con los haitianos, aspiración lógica en una ciudad cuya prosperidad está relacionada con el comercio con la vecina ciudad de Ouanaminthe. Pero casi ninguno estaba dispuesto a aceptar que una persona haitiana pasara a ser parte de la familia. En el medio las opciones se iban alejando de la aceptación según se acercaban a la intimidad. Y a la inversa, se alejaban del rechazo según se acercaban al utilitarismo pragmático.

Una pregunta crucial era si consideraban beneficiosa la relación con la ciudad haitiana, a lo que una abrumadora mayoría respondió afirmativamente, y otro tanto creía que si se eliminaban esas relaciones, Dajabón sería más pobre. Es interesante anotar que muchas de las personas que se pronunciaban por mantener e incrementar las relaciones transfronterizas, al mismo tiempo creían que los haitianos eran productores de atraso, que quitaban puestos de trabajo y oportunidades a los dominicanos y que estaban interesados en invadir a República Dominicana. Una perfecta muestra de esquizofrenia política producto del solapamiento de una realidad de intercambios provechosos, una apertura fronteriza incompleta y una prédica racista y antihaitiana que es parte de la ideología dominante.

Sobre la fronteras chileno-peruana yacen dos ciudades que componen un típico cut: Arica y Tacna. Esta línea fronteriza fue el resultado de una guerra que perdieron Perú y Bolivia, y con ello parte de su territorio que fue incorporado a la vencedora República de Chile. Ha sido una frontera organizada sobre los resentimientos de una "pax castrense", al decir de González (2006). Pero ello no ha impedido la multiplicación de los lazos económicos, sociales y culturales que modelan la vida cotidiana de ambas 
ciudades. Cuando los aires chovinistas han soplado con fuerza sobre el territorio fronterizo, los actores locales -municipios, sociedad civil, grupos empresariales- se han ocupado de explicar que los problemas entre Lima y Santiago deben resolverse sin afectar la relación que alimenta las dinámicas urbanas.

6. Construcción de relaciones institucionales formales, desde el Estado y la sociedad civil. Finalmente, los CuT implican inevitablemente relaciones políticas e institucionales formales que intentan acomodar algún esquema de gobernabilidad que tome en cuenta la dualidad. A mayor la interacción de las variables antes anotadas, mayor la interacción institucional formal, sea desde los Estados o desde las sociedades civiles.

Estas relaciones se pueden expresar en dos niveles principales. El primero da cuenta de la formalización binacional e incluye acuerdos integracionistas, arreglos de cooperación o contactos puntuales en torno a los cuatro temas claves que rigen toda frontera: comercio, migración, seguridad y medio ambiente. Diría que es un nivel necesario para conseguir un clima de entendimientos y de predictibilidad que toda sociedad requiere.

Muchos conflictos limítrofes - como los que hoy cruzan las fronteras chileno-peruana o nicaragüense-costarricense- son asuntos que no conciernen a las comunidades fronterizas, que tratan de mantener sus niveles de intercambios a pesar de los conflictos; y que siempre son perjudicadas por éstos. Aun cuando no haya conflictos territoriales explícitos, los vacíos normativos e institucionales no son los mejores escenarios para el desarrollo de las fronteras. Uno de los graves problemas de la frontera dominico/haitiana es que ha ocurrido sin arreglos binacionales mínimos, de manera que los intensos flujos comerciales y migratorios transcurren sobre precariedades institucionales que a menudo erupcionan y crean conflictos mayores.

Pero la institucionalización binacional, no es una condición positiva per se, en particular cuando prescinde del reconocimiento de los arreglos políticos y normativos, y de las prácticas sociales del segundo nivel que nos interesa destacar: el nivel local o propiamente transfronterizo. Cuando la formalización legal e institucional de las 
fronteras ocurre desde miradas centralistas y nacionalistas, los CUT son sometidos a presiones de cierres y delimitaciones tan graves como las que tienen lugar cuando no hay ninguna institucionalidad. Las historias son perfectamente conocidas: militarizaciones, persecuciones de prácticas sociales ancestrales, y descalificaciones de los intercambios económicos “informales". Héctor Jaquet (2008), en un apasionante artículo sobre las fronteras Brasil-Argentina-Paraguay ha descrito de manera vívida las repercusiones del Mercado Común del Sur (Mercosur):

En relación con el MERCosur, contrariamente a lo esperado, su implementación desde 1991-94 no trajo la integración de los pueblos tan declamada en los tratados, sino más bien vino a interrumpir y a añadir más nivel de conflicto a un marco histórico de relaciones entre los habitantes de las dos orillas. Las políticas integracionistas pronto marcaron la existencia de un mercosur "desde arriba" y "para los de arriba" y otro que padecen "los de abajo". En términos de algunos agentes fronterizos, "un mercosur de primera" que habría beneficiado a los grandes empresarios y a los circuitos transnacionales, y "un MERCosur de segunda”, que afectó notablemente a las poblaciones locales fronterizas periféricas (p. 57).

A escala local, los CuT tienden a ensayar fórmulas de gobernabilidad mediante acuerdos locales que involucran a ayuntamientos, instituciones estatales desconcentradas y a la sociedad civil. Hay múltiples experiencias de esa naturaleza que ameritarían un estudio específico o acerca de los logros y fracasos de los intentos de planificación y gestión cooperada, similares a los que se han ensayado en la frontera México-Estados Unidos y que han sido recopilados por Fuentes y Peña (2005). Y que con seguridad mostrarían que los cut han sido activos laboratorios de lo que hoy se denomina "paradiplomacia", aun cuando sus actores no hayan tomado plena conciencia de ello.

Con frecuencia estos acercamientos son mucho más ricos en procedimientos funcionales que en normativas, por lo que ocultan al observador un proceso de interacciones superior a la apariencia formal. En la frontera dominico/haitiana, a pesar de la presencia de una extensa parafernalia de 
instituciones y protocolos de cooperación, los únicos espacios binacionales que han funcionado en el último decenio han sido forjados por organismos locales en la frontera. Su muestra más acabada es la existencia de un Comité Intermunicipal Transfronterizo que agrupa a los municipios en una de las partes más activas del borde y que ha generado - con el apoyo de la cooperación internacional- diversos proyectos productivos, de empleos y de provisión de servicios técnicos para ambos lados de la frontera.

Es evidente que los CuT no pueden ser abordados desde las perspectivas políticas tradicionales que Leresche y Saez (2004) han denominado "topocráticas" y que están basadas en la visión tradicional de un centro y una periferia fronteriza, y la percepción de esta última como filtro y contén del otro. En su lugar, vuelvo a los autores antes mencionados, se necesita una visión "adhocrática" de "gobernanza sináptica” y reemplazo (para estos fines) del discurso nacionalista por otro de valores locales compartidos.

\section{Un tema para seguir discutiendo}

Lo que hasta aquí hemos discutido se refiere a los intentos de conceptualización de un fenómeno sociológico creciente: la urbanización de las fronteras y el surgimiento de aglomeraciones de igual signo que tienden a comportarse - con éxitos diferentes-como sistemas. Es lo que Herzog (1990) señaló como "metrópolis transfronterizas"; Peña (2008) llamaba "conurbaciones transfronterizas"; Valero (2004) calificaba como "ciudades transfronterizas" y aquí hemos denominado "complejos urbanos transfronterizos".

Esta discusión conceptual nos invita a reflexionar en dos sentidos: en un primer plano, se trata de mirar hacia el crucial tema de cómo organizar la gestión cooperada de aquellos espacios y flujos que efectivamente son compartidos, y que escapan tanto a las institucionalidades netamente nacionalistas como a las integraciones binacionales. Es un asunto que no sólo tiene fines muy prácticos en cuanto a una percepción del desarrollo local que optimice la relación costos/beneficios que tiene toda relación transfronteriza, sino que también muestre caminos de entendimientos y consensos en escenarios binacionales que en ocasiones oscilan entre la hostilidad latente y la hermandad retórica. 
Una segunda cuestión sería aprovechar la oportunidad para producir un debate sobre bases comparadas que coloque a nuestro continente en este escenario académico especializado, en el que hoy sólo aparece como una nota al pie. Desafortunadamente, las discusiones sobre temas fronterizos que predominan en la academia mundial son las que tratan las realidades noratlánticas y se nutren de bibliografías en inglés. Es responsabilidad de nuestros académicos e intelectuales generar un debate calificado que no pueda ser obviado, pero para ello requerimos una producción intelectual con aspiraciones universalistas que evite los atrincheramientos nacionalistas y proteccionistas de nuestras especificidades.

Lo que hemos presentado es sólo una invitación a ese debate. La propuesta de los complejos urbanos transfronterizos sólo aspira a brindar una serie de apuntes para una metodología abierta sobre un tema que involucra las vidas cotidianas de millones de personas en el continente. Si el concepto perdurara incólume, entonces habría fracasado en sus intenciones.

\section{Bibliografía}

Alegría, T. (1992). Desarrollo urbano en la frontera México-Estados Unidos. México: Consejo Nacional para la Cultura y las Artes.

Alegría, T. (2000). Juntos pero no revueltos: Ciudades en la frontera MéxicoEstados Unidos. Revista Mexicana de Sociología, 62(2), 89-107.

Alegría, T. (2008). ¿Existen las metrópolis transfronterizas? En H. Dilla (Ed.), Ciudades en la frontera (pp. 127-167). Santo Domingo: Editora Manatí.

Alvarez, R. (1995). The Mexican-us border: The making of an anthropology of borderlands. Annual Review of Anthropology, 24, 447-470.

Anderson, J. y O'Dowd, L. (1999). Borders, border regions and territoriality: Contradictory meanings and changing significance. Regional Studies, 33(7), 593-604.

Aranda, G., Ovando, C. y Corder, A. (2010). Experiencias paradiplomáticas en la región de Tarapacá y su proyección subregional. Estudios Internacionales, (165), 33-74.

Bauman, Z. (2004). La sociedad sitiada. México: Fondo de Cultura Económica.

Bello, D. (2012). La triple frontera del Paraná. Santiago: Ril Editores.

Bitar, J. (2011). El establecimiento natural de una región transfronteriza en el área metropolitana binacional de Cúcuta y San Cristóbal. En J. M. Sandoval, 
R. Álvarez y L. Saavedra (Eds.), Integración geoestratégica, seguridad, fronteras y migración en América Latina (69-92). Quito: Universidad de los Andes.

Bustamante, A. M. (2004). Subnacionalismo en la frontera. Territorios (10-11),127144.

Buursink, J. (2001). Binational cities. GeoJournal, 54(1), 7-19.

De Jesús, S. (2010). ¿Cómo son percibidos los haitianos en la frontera? En H. Dilla (Ed.), La frontera dominico-haitiana (pp. 283-314). Santo Domingo: Editora Manatí.

Dear, M. y Leclerc, G. (2003). Postborder City: Cultural Spaces of Bajalta California, Londres: University of Southern California.

Dilla, H. (2007). República Dominicana: La nueva cartografía fronteriza. Caribbean Studies, 35(1), 2007.

Dilla, H. (2008). Las ciudades en la frontera: Introducción a un debate. En H. Dilla (Ed.), Ciudades en la frontera (pp. 17-29). Santo Domingo: Editora Manatí.

Ehlers, N. (2001). The utopia of the binational city. GeoJournal, 54(1), 21-32.

Ehlers, N. y Buursink, J. (2000). Binational cities: People, institutions and structures. En M. V. der Velde y H. V. Houtum (Ed.), Borders, Regions and People (pp. 185-201). Londres: Pion Limited.

Félix, G., Zepeda, E. y Castro, D. (1996). Desarrollo regional y los servicios al productor en los corredores fronterizos del norte de México. En A. Mungaray y M. García (Coords.), Desarrollo fronterizo y globalización. México: Anuies.

Fuentes, C. y Peña, S. (2005). Planeación binacional y cooperación transfronteriza entre México y Estados Unidos. México: Uajc-El Colegio de la Frontera Norte.

Glassner, M. y De Blij, H. (1980). Systematic Political Geography. Nueva York: John Wiley and Sons.

González, S. (2006). Densidad, integración y conflicto en la triple frontera. En A. Bello, La integración y el desarrollo social fronterizo (pp. 25-42). Bogotá: Convenio.

Grimson, A. (2000). ¿Fronteras políticas vs. fronteras culturales? En A. Grimson (Comp.), Fronteras nacionales e identidades (pp. 9-49). Buenos Aires: Ciccus.

Herzog, L. (1990). Where North Meets South. Austin: University of Texas Press.

Herzog, L. y Sohn, C. (2014). The cross-border metropolis in a global age: A conceptual model and empirical evidence from the US-Mexico and European border. Regions, Global Society, DoI: 10.1080/13600826.2014.948539

Jaquet, H. (2008). Más allá de las fronteras, las fronteras. En H. Dilla (Ed.), Ciudades en la frontera (pp. 33-66). Santo Domingo: Editora Manatí.

Jessop, B. (2001). The political economy of scale. En M. Perkman y Ngai-Ling Sum (Eds.), Globalization, Regionalization and Cross Border Regions (pp. 25-48). Londres: Palgrave.

Kolossov, V. (2005). Border studies: Changing perspectives and theoretical approaches. Geopolitics, 10(4), 606-632. 
Haroldo Dilla Alfonso / Los complejos urbanos transfronterizos en América Latina

Leimgruber, W. (2005). Boundaries and transborder relations, or the hole in the prison wall. GeoJournal, 64(3), 239-248.

Leresche, J. F. y Saez, G. (2004). Political frontier regimes: Towards crossborder governance? En M. Perkam y Ngai-Ling Sum (Ed.), Globalization, Regionalization and Cross-Border Regions. Londres: Palgrave.

Martínez, O. (1994). Border People: Life and Society in the US-Mexico Borderland. Tucson: The University of Arizona Press.

Montenegro, S. y Giménez, V. (2006). La triple frontera: Globalización y construcción del espacio. Madrid: Mino y Dávila.

Muñoz, F. (2008). Urbanalización. Barcelona: GGmixta.

Ohmae, K. (1991). The Borderless World. Nueva York: Harper Collin.

Peña, S. (2008). Ciudades y fronteras: Los retos de la planificación transfronteriza. En H. Dilla (Ed.), Ciudades en la frontera (pp. 263-283). Santo Domingo: Manatí.

Perkman, M. y Sum, Ngai-Ling (2001). Globalization, regionalization and cross border regions: Scales, discourses and governance. En M. Perkman y NgaiLing Sum (Eds.), Globalization, Regionalization and Cross Border Regions (pp. 3-24). Londres: Palgrave McMillan.

Rouviere, L. (2009). ¿Un territorio político transfronterizo? Formas de legitimación de una experiencia de legitimación de una experiencia de acción política intermunicipal. Si Somos Americanos. Revista de Estudios Transfronterizos, 9(2), 13-29.

Sohn, C. (2013). The border as a resource in the global urban space: A contribution to the cross-border metropolis hypothesis. International Journal of Urban and Regional Research, 1(10), 1-18.

Sohn, C. (2014). Modelling cross-border integration: The role of borders as a resource. Geopolitics, 19(3), 587-608.

Valero, M. (2002). Las fronteras como espacio de integración. Caracas: Tropykos.

Valero, M. (2008). Ciudades transfronterizas e interdependencia comercial en la frontera Venezuela/Colombia. En H. Dilla (Ed.), Ciudades en la frontera (pp. 67-96). Santo Domingo: Manatí.

Vila, P. (2000). Crossing Borders, Reinforcing Borders: Social Categories, Metaphors, and Narratives Identities on the U.S.-Mexico Frontier. Austin: University of Texas Press.

Wright, E. O. (1994). Clases. Madrid: Siglo xxı. 